\title{
TERESA GISBERT Y LA ARQUEOLOGIA ANDINA
}

\author{
Claudia Rivera Casanovas ${ }^{1}$
}

Hablar de Teresa Gisbert implica posicionarse en un punto en el que convergen múltiples lecturas y visiones del pasado y presente en el área andina y en las tierras bajas tan próximas e interconectadas. Sus aportes en varios campos del conocimiento como la arquitectura, la historia del arte, la antropología y la arqueología se originaron, como ella bien decía, en su infancia y adolescencia en la ciudad de La Paz. Sus primeros años los pasó en un mundo culturalmente diverso en el que la cultura catalana y española de sus padres se entrelazó con la cultura criolla boliviana y más enigmáticamente con el mundo indígena que convivía con las dos primeras, tan cercano y a la vez distante dentro de las mismas paredes de su casa y en el entorno citadino. Llamaba poderosamente su atención cómo gentes y prácticas culturales tan distintas podían convivir, yuxtaponerse y tolerarse de una forma tan sincrética y dinámica. Ellas se expresaban de forma tangible en grupos sociales que se distinguían por un idioma propio, vestimentas singulares, además de costumbres y formas de pensar distintas. Esta mezcla de culturas le intrigó en demasía y la llevó a desarrollar ideas y pensamientos sobre la coexistencia de sociedades superpuestas y los mecanismos por los cuales podían funcionar conjuntamente (Foto 1). En otras palabras, el presente etnográfico del que ella fue parte, detonó su interés por entenderlo buscando sus orígenes en un pasado de larga duración (Rivera Casanovas 2016). Sus vivencias personales le dieron la oportunidad de conocer y acercarse a personas y situaciones desde adentro, además de su conocimiento de regiones y geografías en Bolivia, le sirvieron de referencia y marco comparativo para luego ir contrastando datos con otras regiones de los Andes, América, Europa y África.

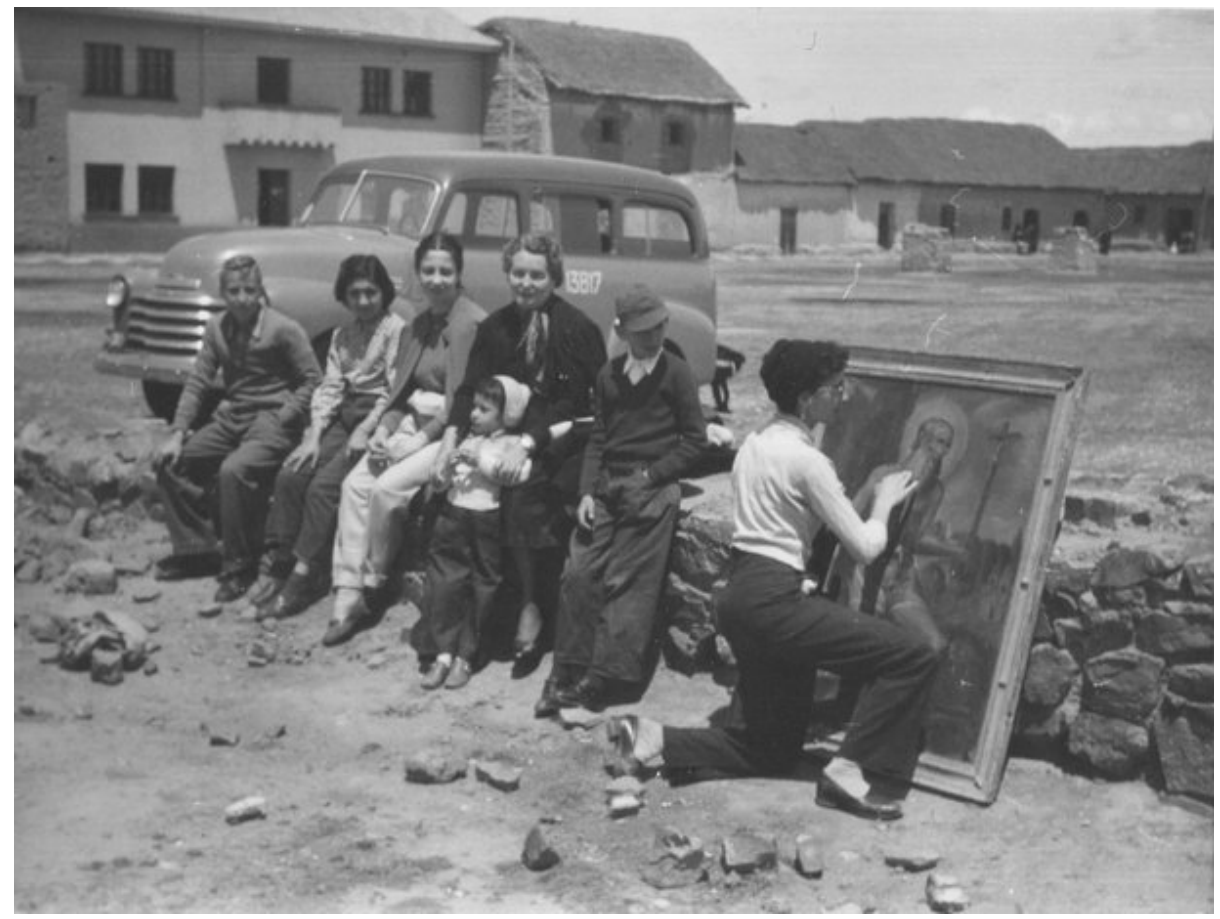

Foto 1. Trabajo de campo en 1958 estudiando un cuadro en el atrio de una iglesia del altiplano boliviano, junto a familiares (foto de Teresa Gisbert).

\footnotetext{
${ }^{1}$ Instituto de Investigaciones Antropológicas y Arqueológicas, Universidad Mayor de San Andrés, La Paz, Bolivia. clauri68@yahoo.com
} 
Una vez concluidos sus estudios de arquitectura, siendo catedrática en la Facultad de Arquitectura de la Universidad Mayor de San Andrés en La Paz, y ya casada con el arquitecto José de Mesa, iniciaron juntos un vasto proyecto de indagación arquitectónica, artística, histórica y cultural en una perspectiva de larga duración. Es así que desde la década de 1950 del siglo pasado publicaron variados libros y artículos. Sin embargo, sus aportes no solamente se circunscribieron a un campo teórico del conocimiento. Desde muy temprano tomaron acción para posicionar en el contexto boliviano e internacional la producción cultural pasada expresada en distintos soportes y materialidades. Hicieron gestiones y sentaron políticas para la creación de museos y la conservación de monumentos y objetos prehispánicos e históricos. Mucho es lo que se podría decir de esta amplia labor de décadas, sin embargo, en este pequeño homenaje quiero enfocarme principalmente en aquellos aspectos relacionados con el trabajo de Gisbert en torno a la arqueología andina.

Cuándo el año 2014 hice una entrevista a Teresa Gisbert y le pregunté sobre cómo pensaba sus aportes al campo de la arqueología, ella, sorprendida me dijo -“"realmente mi trabajo contribuyó a la arqueología?-, nunca lo hubiera pensado así". La modestia de su comentario contrasta con la variedad de trabajos que de manera directa o indirecta la vincularon con el quehacer arqueológico y antropológico. Dichas contribuciones se destacan, en cierta medida, por miradas novedosas y renovadas sobre aspectos que con anterioridad no se habían pensado. En un ámbito dominado por personalidades masculinas durante gran parte del siglo XX, los trabajos de Gisbert se destacaron por su forma original de acercarse a un pasado prehispánico y su sensibilidad para reconocer los procesos de transición coloniales desde tres ámbitos de trabajo que se apoyaron fuertemente en la lectura e interpretación de documentos escritos: la arquitectura, la iconografía y el arte textil.

\section{Arquitectura y ocupación del espacio}

Aunque las investigaciones de Gisbert, muchas de ellas junto a su esposo, se enfocaron en arquitectura colonial pública y religiosa y en el diseño y evolución de los espacios urbanos, también le dedicó atención a conjuntos prehispánicos como Akapana en Tiwanaku (Mesa y Gisbert 1957) demostrando que se trataba de una pirámide artificial con funciones religiosas, similar a las de Mesoamérica. También interpretó el diseño urbano de Tiwanaku con reconstrucciones planimétricas y tridimensionales del centro cívico ceremonial, así como un estudio del arte precolombino en Bolivia (Mesa y Gisbert 1955, 1967). En el campo de la arquitectura colonial su trabajo sobre las iglesias doctrineras del altiplano boliviano en cuanto al diseño de la planta, la disposición espacial y otros aspectos del diseño identificando sorprendentes similitudes con el planeamiento de los espacios religiosos prehispánicos que mostraban elementos de sincretismo cultural. Su estudio sobre historia de la vivienda y asentamientos humanos en Bolivia (1988) analiza la evolución de los asentamientos prehispánicos desde el período Formativo (1800 AC-500 DC) hasta la ocupación Inca (1450-1535 DC), seguida por sus características durante los períodos Colonial y Republicano. Constituye una referencia sobre la evolución de la vivienda, los sistemas constructivos y los asentamientos humanos a través del tiempo, empleando nociones relacionadas con los patrones de asentamiento usados en arqueología.

Sin duda, uno de sus aportes más interesantes en el campo arqueológico es el estudio de los chullpares polícromos en el Río Lauca, Oruro. Gisbert se refirió al tema como una de las experiencias más impactantes y sorprendentes en su vida de investigadora. No entendía como hasta la década del 90 del siglo pasado nadie hubiese reportado las torres funerarias pintadas y que hubieran pasado desapercibidas al ser tan llamativas y únicas (Rivera Casanovas 2016:78). Su trabajo presenta una visión sobre la construcción de un paisaje sacralizado histórico y mítico por parte de los Carangas e Incas. Analizó los diseños plasmados en las paredes de las estructuras, relacionando los motivos romboidales con la trayectoria solar y con tocapus presentes en los textiles y la cerámica incaica. Planteó que los chullpares fueron tumbas reales de los señores Carangas aliados con los Inca y también de líderes incaicos. Su iconografía representaría las insignias reales de Tupac Yupanqui y la costumbre de envolver las tumbas con textiles de rica iconografía (Gisbert 1994). Con este estudio puso en realce la importancia de los textiles como objetos relacionados con el poder, prestigio y simbolismo prehispánico. En el mismo sentido, van las indagaciones sobre paisajes sagrados, el culto a las montañas y su relación con antiguos dioses como en el caso de Pachacamac y varios cerros sagrados del altiplano central y sur de Bolivia (Foto 2).

Ya dentro del campo etnohistórico propuso la hipótesis de la invasión aymara desde el sur como factor para el colapso de Tiwanaku. Dicha migración habría seguido un eje norte sur y estaría relacionada con el origen de Lupacas, Pacajes y otros grupos (1980, 1994). Aunque los estudios arqueológicos basados en prospecciones regionales sistemáticas demuestran una continuidad cultural tras el colapso de Tiwanaku en la cuenca del Titicaca, el postulado no deja de ser interesante porque abre la discusión sobre movimientos poblacionales en los siglos posteriores a la caída de esta entidad política. 


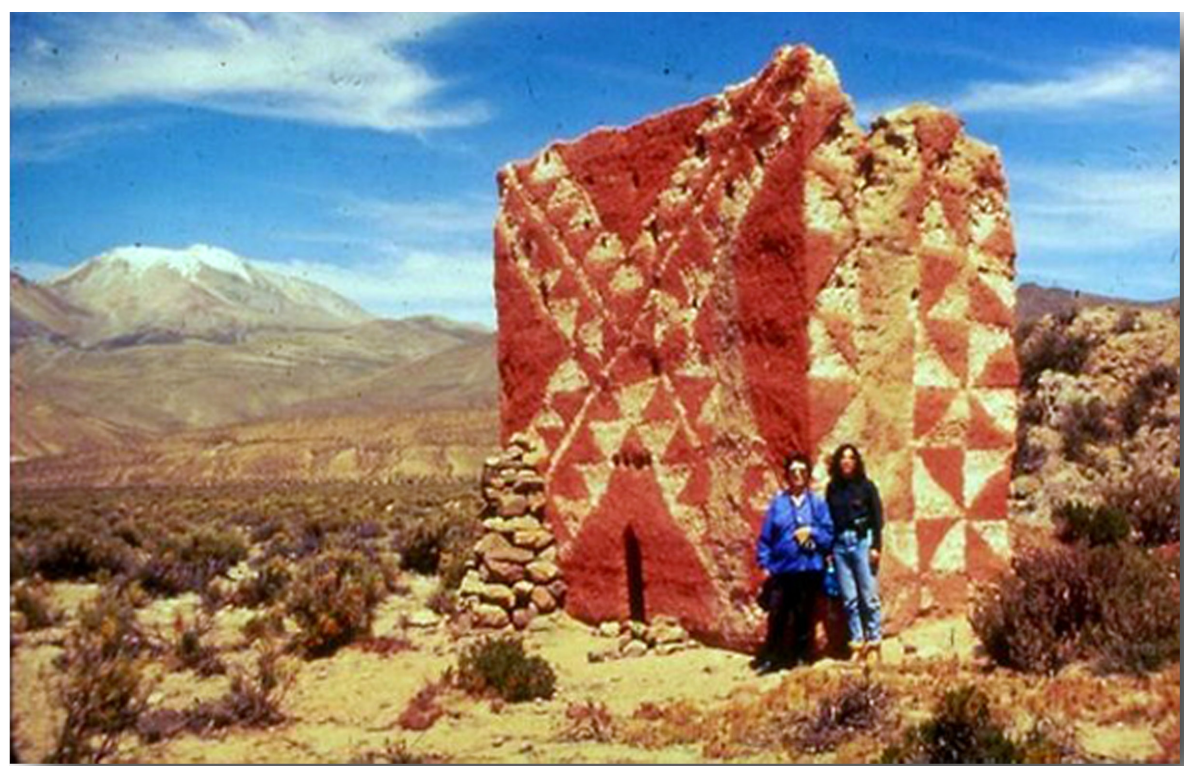

Foto 2. Teresa Gisbert y Elvira Salinas en los chullpares del río Lauca, Oruro 1996 (foto de Teresa Gisbert).

\section{Iconografía andina}

Los estudios de Gisbert sobre la iconografía colonial son de gran valor al mostrar un mundo rico en lecturas y mensajes en el que no se había pensado con anterioridad (1980). El barroco andino fue una gran contribución a los estudios americanos y mundiales que abrió muchas líneas de investigación sobre estas temáticas. En esta perspectiva sus trabajos sobre la iconografía colonial vinculada con el mundo prehispánico le permitieron explorar una dimensión mítica e ideológica que no se perdió con la conquista española, como se pensaba, sino que sobrevivió y se transformó dentro de nuevos cánones culturales y políticos. Sus lecturas son pioneras para entender la sacralización de los paisajes culturales en el altiplano boliviano y cómo los relatos coloniales impregnados de una fuerte carga cristiana tuvieron como base una diversidad de mitos prehispánicos. La relación virgen-montaña es uno de los casos más conocidos, así como Tunupa relacionado con el fuego y el rayo con Santo Tomás o San Bartolomé. Del mismo modo, vemos la relación de las sirenas con deidades prehispánicas como Umantuu y Quesintuu, las mujeres peces del eje acuático Titicaca-Desaguadero-Poopó. Las representaciones de animales y plantas nativos en el arte virreinal se vinculan con lo prehispánico y se plasman en iglesias y portadas. Monos, felinos y serpientes, deidades prehispánicas, se incorporan dentro del mundo colonial. En síntesis, los trabajos iconográficos de Gisbert mostraron continuidades y sincretismos de larga duración dentro de un proceso en el que los estudiosos priorizaron visiones de conquista, dominio e imposición sin llegar a entender a cabalidad las complejas dinámicas sociales y culturales que dieron lugar a nuevas formas culturales.

\section{Los textiles en los andes como formas de expresión poco valoradas}

Los textiles en el mundo andino son objetos de alto valor simbólico y social, fueron producidos mediante una tecnología compleja. Para la década de 1980 poco se había hecho en Bolivia para estudiarlos, siendo Teresa Gisbert, junto a Silvia Arze y Martha Cajías (1987), una de las pioneras en este campo. La síntesis realizada sobre los estilos textiles regionales en Bolivia considera una visión de larga duración que parte de la arqueología de distintas regiones identificando estilos textiles prehispánicos y sus continuidades o rupturas durante los períodos Colonial y Republicano. A partir de un exhaustivo trabajo de campo etnográfico, además de la consulta de fuentes escritas y pictóricas, abordó a los textiles dentro de su contexto cultural prehispánico, histórico y contemporáneo, considerando sus funciones rituales y conceptuales dentro de las sociedades pasadas y del Imperio Inca. Estudió las técnicas textiles prehispánicas y etnográficas, los tipos de prendas de vestir y el vocabulario de la lengua aymara de Bertonio para identificar procesos tecnológicos, las características de los artesanos y las valoraciones y significados de las prendas. Su obra es un pilar en los estudios sobre tejidos andinos y constituye una fuente de consulta e inspiración para trabajos en la temática (Foto 3). 


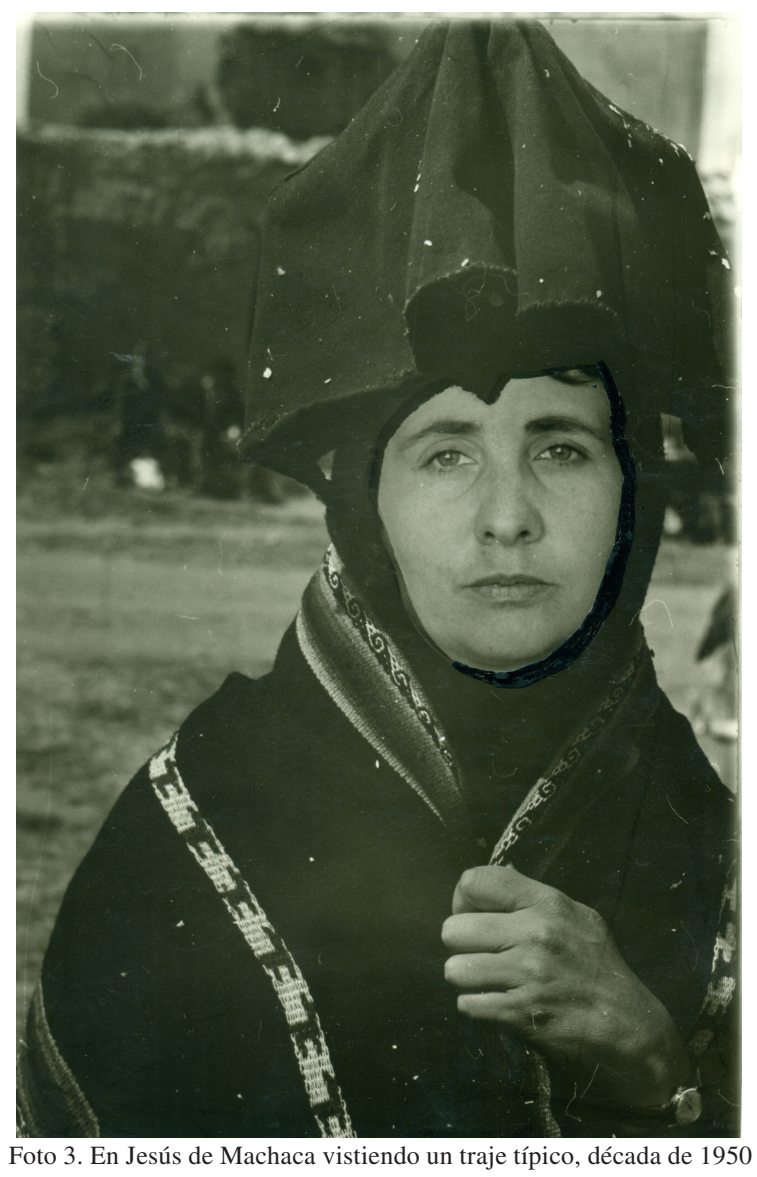

(foto de Teresa Gisbert).

Teresa Gisbert impartió sus conocimientos a varias generaciones de arquitectos y más indirectamente de historiadores y arqueólogos. Sus trabajos han servido de inspiración y debate en el campo de la arqueología andina. Finalmente se debe reconocer la influencia de Gisbert para el desarrollo de estudios interdisciplinarios, desde la historia, la arquitectura y el arte, buscando aproximaciones enriquecedoras sobre pasado andino y su diversidad cultural. Teresa Gisbert fue una mujer excepcional que, a lo largo de su vida profesional y académica, aportó a los estudios andinos e inspiró los trabajos de nuevas generaciones.

\section{Referencias Citadas}

Gisbert, T. 1980. Iconografía y Mitos Indígenas en el Arte. Gisbert y Cia., La Paz.

Gisbert, T. 1988. Historia de la Vivienda y los Asentamientos Humanos en Bolivia. Academia Nacional de Ciencias de BoliviaInstituto Panamericano de Geografía e Historia, México D.F.

Gisbert, T. 1994. El señorío de los Carangas y los chullpares del río Lauca (colaboración con Juan Carlos Jemio y Roberto Montero). Revista Andina 2:427-485.

Gisbert, T., S. Arze y M. Cajías 1987. Arte Textil y Mundo Andino. Gisbert y Cia., La Paz.

Mesa, J. de y T. Gisbert 1955. Reconstrucción de Taipicala (Tiahuanacu). Khana 9-10.
Mesa, J. de y T. Gisbert 1957. Akapana, la pirámide de Tiwanacu. En Arqueología Boliviana (Primera Mesa Resonda). Dirigido por C. Ponce Sanginés, pp. 140-161. Biblioteca PaceñaAlcaldía Municipal, La Paz.

Mesa, J. de y T. Gisbert 2012. Historia del Arte en Bolivia. Período Prehispánico. Artes Gráficas Sagitario SRL, La Paz.

Rivera Casanovas, C. 2016. Otras miradas: los aportes multidisciplinarios de Teresa Gisbert a la arqueología boliviana. En Otras Miradas Presencias Femeninas en una Historia de Larga Duración, editado por W. Sánches y C. Casanovas, pp. 71-92. Talleres Gráficos Kipus, Cochabamba. 